\title{
A one-pot synthesis of tetrahydroisoquinolin-4-ols via a novel acid-catalyzed rearrangement of 5-aryloxazolidines
}

\author{
Vladimir S. Moshkin*, Vyacheslav Ya. Sosnovskikh \\ Department of Chemistry, Ural Federal University, Pr. Lenina 51, 620000 Ekaterinburg, Russia
}

\section{A R T I C L E I N F O}

\section{Article history:}

Received 3 January 2013

Revised 11 February 2013

Accepted 27 February 2013

Available online 7 March 2013

\section{Keywords:}

1,2,3,4-Tetrahydroisoquinolin-4-ols

5-Aryloxazolidines

Nonstabilized azomethine ylide

[3+2] Cycloaddition

Rearrangement

Pictet-Spengler reaction

\begin{abstract}
A B S T R A C T
Benzaldehydes with electron-donating substituents react smoothly with a nonstabilized azomethine ylide derived from sarcosine and formaldehyde to form 5-aryloxazolidines as intermediates, which undergo rearrangement into 2-methyl-1,2,3,4-tetrahydroisoquinolin-4-ols in high yields by simple heating with hydrochloric acid. This one-pot synthesis of tetrahydroisoquinolines can be considered as a formal $[3+3]$ cycloaddition of the azomethine ylide to the aromatic aldehyde.
\end{abstract}

(C) 2013 Elsevier Ltd. All rights reserved.
The chemistry of 4-substituted-1,2,3,4-tetrahydroisoquinolines has attracted considerable attention from the synthetic community due to their distribution in nature and their wide spectrum of biological activity. ${ }^{1}$ Examples of such tetrahydroisoquinolin-4ols include longimammamine (1) and 4,6-dihydroxy-2-methyl1,2,3,4-tetrahydroisoquinoline (2) isolated from Dolichothele longimamma and Theobroma cacao, respectively (Fig. 1). ${ }^{2}$

Synthetic analogs of tetrahydroisoquinolinols $\mathbf{1}$ and $\mathbf{2}$ have been proposed as potential antihypertensive drugs. ${ }^{3 a, b}$ Recently, a Lewis acid catalyzed arylation of tetrahydroisoquinolin-4-ols with thioanisole was reported. ${ }^{3 c}$ This reaction opens a new approach to the synthesis of 4-aryltetrahydroisoquinolines, which can function as serotonin-norepinephrine-dopamine reuptake inhibitors. ${ }^{3 d-f}$ Taking into account other methods of functionalization, the tetrahydroisoquinolin-4-ol core is a valuable building block for the construction of a wide range of isoquinoline derivatives. ${ }^{4 a-i}$

Due to the important applications of this class of compounds, their synthesis has been extensively studied. ${ }^{4}$ There are two classical methods for the preparation of tetrahydroisoquinolin-4-ols. The first is the Pictet-Spengler cyclization of hydroxyphenethylamines 3, which are not easily accessible, ${ }^{4 a-d}$ and the second is the Pomeranz-Fritsch-Bobbitt acid-catalyzed cyclization of $\mathrm{N}$-benzyl- $N$-methylaminoacetaldehyde diethyl acetals $4 .^{4 d-1}$ Both reactions involve multistep procedures and require electron-donating substituents on the aromatic ring of the substrate. The second

\footnotetext{
* Corresponding author. Fax: +7 3432615978.

E-mail address: mvslc@mail.ru (V.S. Moshkin).
}

method is often more efficient due to the fewer number of steps involved from the starting benzaldehydes (Scheme 1).

On the other hand, it is well-known that nonstabilized azomethine ylides generated from sarcosine $(\mathbf{5})$ and formaldehyde, ${ }^{5 a, b}$ or silyl precursor $\mathbf{6}$ in the presence of trifluoroacetic acid ${ }^{5 c, d}$ add to the carbonyl group of benzaldehydes and benzophenone ${ }^{5 \mathrm{e}}$ to form 5-aryloxazolidines $\mathbf{7}$. Their methylene group, the former azomethine ylide cationic center, still has electrophilic character after the cycloaddition step due to the presence of two geminal acceptor atoms and the easy cleavage of the $\mathrm{C}-\mathrm{O}$ acetal bond. It would be reasonable to assume the possibility of the Pictet-Spengler intramolecular recyclization with the formation of the tetrahydroisoquinoline core $\mathbf{8}$ (Scheme 2). In general, these two successive reactions can be considered as a formal [3+3] cycloaddition of the nonstabilized azomethine ylide with the aromatic aldehyde or ketone, followed by proton migration. In this context, and in connection with our interest in the development of azomethine ylide chemistry, ${ }^{6}$ a method based on a 1,3-dipolar cycloaddition
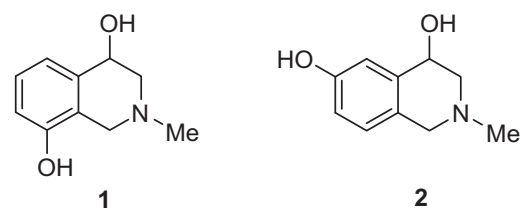

Figure 1. Examples of natural alkaloids containing a tetrahydroisoquinolin-4-ol framework. 
<smiles>[R6]c1cccc(C(O)C#N)c1</smiles><smiles>[R6]c1cccc(C(O)CN)c1</smiles>

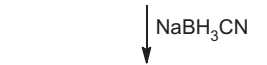

$\checkmark$<smiles>[R6]c1cccc(CN(C)COCC)c1</smiles><smiles>CC(O)C(C)(C)C(C)(C)C=O</smiles><smiles>CN1Cc2ccccc2C(O)C1</smiles>

Scheme 1. The classical syntheses of tetrahydroisoquinolin-4-ols.

followed by an acid-catalyzed rearrangement of the initial 5-aryloxazolidine $\mathbf{7}$ into tetrahydroisoquinoline system $\mathbf{8}$, in a one-pot procedure, attracted our attention. To the best of our knowledge, no such transformation has been reported.

To test the feasibility of the envisioned idea, the reaction of $m$ anisaldehyde with the nonstabilized azomethine ylide derived from sarcosine and formaldehyde was first investigated. We found that refluxing $m$-anisaldehyde, sarcosine, and paraformaldehyde in benzene for $6 \mathrm{~h}$ with azeotropic removal of water resulted in the formation of previously unknown 5-(3-methoxyphenyl)-3-methyloxazolidine (7a) (yield 97\%). The crude product was sufficiently pure according to the ${ }^{1} \mathrm{H}$ NMR spectrum and only a trace (4\%) of the starting aldehyde was observed. To our delight, simple heating of oxazolidine $7 \mathrm{a}$ in $6 \mathrm{M} \mathrm{HCl}$ at $60{ }^{\circ} \mathrm{C}$ resulted in full recyclization into the desired product, 6-methoxy-2-methyl-1,2,3,4-tetrahydroisoquinolin-4-ol $(\mathbf{8 a})^{7,8}$ Subsequent basification of the reaction mixture and extraction with ether gave the rearranged product 8 a a white solid in $89 \%$ isolated yield, based on the starting $m$-anisaldehyde (Scheme 3). Apparently, this intramolecular reaction was mediated by $\mathrm{HCl}$, where protonation of the oxygen

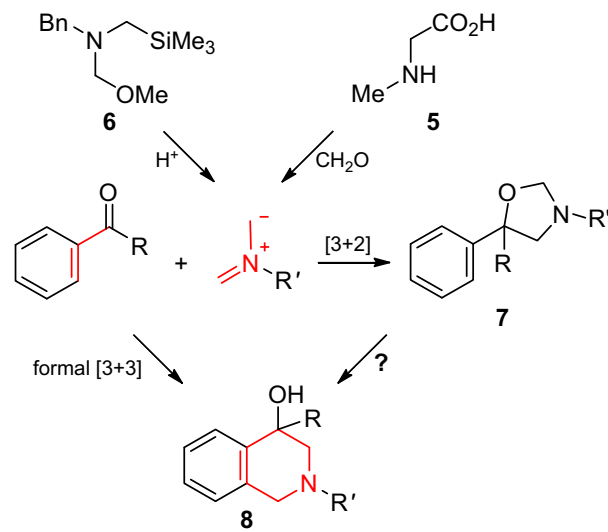

$\mathrm{R}=\mathrm{H}, \mathrm{Ph} ; \mathrm{R}^{\prime}=\mathrm{Me}, \mathrm{Bn}$

Scheme 2. Cycloaddition of aromatic aldehydes and ketones with azomethine ylides.
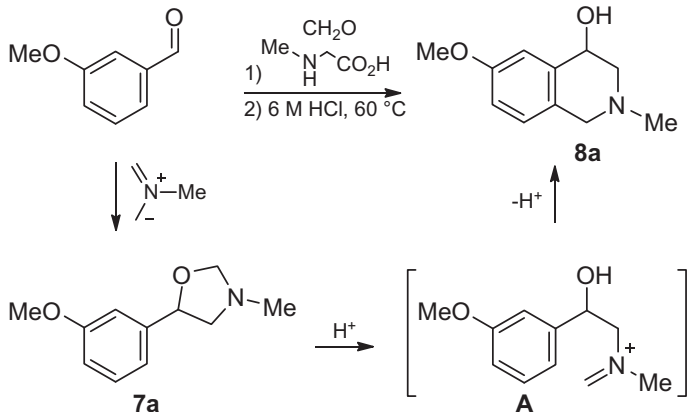

Scheme 3. One-pot synthesis of the tetrahydroisoquinolin-4-ol 8a.

Table 1

Yields and melting points of the products $8 \mathbf{a}-\mathbf{f}$

Entry

a This compound was mentioned in Ref. 4c without any data.

b $\mathrm{Mp} 127-128{ }^{\circ} \mathrm{C}$ (Ref. 4e,f), mp $124-126^{\circ} \mathrm{C}$ (Ref. $4 \mathrm{~g}$ ).

c $\mathrm{Mp}$ of the hydrochloride $189-191^{\circ} \mathrm{C}$ (Ref. $4 \mathrm{~b}$ ).

d This compound was reported in Ref. 4k without any data, only the mp $106-$ $108{ }^{\circ} \mathrm{C}$ was described.

e This compound was reported in Ref. 10a without any data, only the mp $145^{\circ} \mathrm{C}$ of the maleate was given.

atom facilitates breakdown of the oxazolidine ring to give cationic intermediate $\mathbf{A}$, which acts as an internal electrophile.

With optimal conditions for the one-pot synthesis of tetrahydroisoquinolinol 8a in hand, reactions with other aromatic aldehydes bearing electron-donating substituents were investigated. As can be seen from Table 1 , the reactions of veratraldehyde, 3,4,5-trimethoxybenzaldehyde, ${ }^{9}$ O-benzyl vanillin, and 3,4-methylendioxybenzaldehyde proceeded smoothly to afford the desired 
products $\mathbf{8 b}-\mathbf{e}$ in $62-87 \%$ yields. Tetrahydroisoquinoline $\mathbf{8 b}$ has been reported earlier. ${ }^{4 \mathrm{e}-\mathrm{g}}$ Using this approach we were also able to obtain 5-methyl-4,5,6,7-tetrahydrothieno[3,2-c]pyridin-7-ol (8f) from thiophene-2-carbaldehyde in 63\% yield under the same conditions, which may be of interest as a therapeutically valuable compound. ${ }^{10}$ However, all our attempts to rearrange the oxazolidines obtained from benzaldehyde and anisaldehyde failed (the former at a higher temperature led to partial hydrolysis of the oxazolidine ring with extrusion of formaldehyde, while the latter gave an insoluble dark gum). The lack of reactivity in these cases was apparently due to the low nucleophilicity of the benzene ring. These results clearly show that at least one electron-donating meta-substituent must be present on the aromatic aldehyde for the successful electrophilic aryloxazolidine-tetrahydroisoquinoline rearrangement. The structures of products 8a-f were characterized by IR, ${ }^{1} \mathrm{H}$, and ${ }^{13} \mathrm{C}$ NMR spectral data as well as by elemental analysis.

Comparing with the Pictet-Spengler cyclization of the corresponding hydroxyphenethylamines, this reaction proceeds with high regioselectivity. No 8-methoxy regioisomer was observed. ${ }^{2 a}$ Also it should be noted that the preparation of $N$-benzyl- $N$ methylaminoacetaldehyde diethyl acetal from $m$-anisaldehyde followed by Pomeranz-Fritsch-Bobbitt cyclization leads to 7-methoxytetrahydroisoquinoline, while the reaction described here gives 6-methoxy isomer and is a good addition to the classical method. Moreover, unlike both previously known approaches for the synthesis of tetrahydroisoquinolines from aromatic aldehydes, this process does not require any reducing agent or chromatographic purification of the intermediate liquid oxazolidines, and thereby greatly facilitates the preparation of the target tetrahydroisoquinolinols.

In conclusion, we have developed a simple and convenient onepot method for the synthesis of 2-methyl-1,2,3,4-tetrahydroisoquinolin-4-ols from aromatic aldehydes bearing electron-donating substituents and an azomethine ylide derived from sarcosine and formaldehyde, via a novel aryloxazolidine-tetrahydroisoquinoline rearrangement. Compared with the previously known procedures, our method shows several advantages, the main of which are simplicity, efficiency, and easy availability of the starting materials. Further application of this reaction for the construction of substituted tetrahydroisoquinolines and their heteroanalogs is underway in our laboratory and will be reported in due course.

\section{Acknowledgment}

This work was supported financially by the RFBR (Grant 12-0331036).

\section{Supplementary data}

Supplementary data associated with this article can be found, in the online version, at http://dx.doi.org/10.1016/j.tetlet.2013. 02.087 .

\section{References and notes}

1. (a) Chemistry of Heterocyclic Compounds Isoquinolines; Taylor, E. C., Weissberger, A., Grethe, G., Eds.; John Wiley \& Sons: New York, 1981. Vol. 38; (b) Rozwadowska, M. D. Heterocycles 1994, 39, 903-931; (c) Charifson, P. S Drugs Future 1989, 14, 1179-1185.
2. (a) Ranieri, R. L.; McLaughlin, J. L. J. Org. Chem. 1976, 41, 319-323; (b) Ranieri, R. L.; McLaughlin, J. L. Lloydia 1977, 40, 173-177; (c) Kenyhercz, T. M.; Kissinger, P. T. Lloydia 1978, 41, 130-139.

3. (a) Grethe, G.; Lee, H. L.; Uskokovic, M. R. U.S. Patent 3,772,304, 1973; Chem. Abstr. 1974, 80, 59880.; (b) Grethe, G.; Lee, H. L.; Uskokovic, M. R. U.S. Patent 3,629,265, 1971; Chem. Abstr. 1972, 76, 113088.; (c) Deng, X.; Liang, J. T.; Liu, J.; McAllister, H.; Schubert, C.; Mani, N. S. Org. Process Res. Dev. 2007, 11, 10431050; (d) Rheiner, A. DE Patent 2,062,001, 1971; Chem. Abstr. 1971, 75, 129683.; (e) Molino, B. F.; Berkowitz, B.; Cohen, M. U.S. Patent 20,060,111,394, 2006; Chem. Abstr. 2006, 144, 488538.; (f) Molino, B. F.; Liu, S.; Berkowitz, B. A.; Guzzo, P.; Beck, J. P.; Cohen, M. WO Patent 2,006,020,049; Chem. Abstr. 2006, $144,254149$.

4. (a) Kondo, T.; Tanaka, S. J. Pharm. Soc. Jpn. 1930, 119-121; (b) Friedman, O. M.; Parameswaran, K. N.; Burstein, S. J. Med. Chem. 1963, 6, 227-229; (c) Simig, G.; Schlosser, M. Tetrahedron Lett. 1994, 35, 3081-3082; (d) Quessy, S. N.; Williams, L. R. Aust. J. Chem. 1979, 32, 1317-1327; (e) Lesèche, B.; Gilbert, J.; Viel, C. J. Heterocycl. Chem. 1981, 18, 143-153; (f) Umezawa, B.; Hoshino, O.; Terayama, Y. Chem. Pharm. Bull. 1968, 16, 180-182; (g) Moreno, I.; SanMartin, R.; Tellitu, I.; Domínguez, E. Heterocycles 1999, 51, 2311-2320; (h) Dyke, S. F.; Bather, P. A.; Garry, A. B.; Wiggins, D. W. Tetrahedron 1973, 29, 3881-3888; (i) Morita, Y.; Imaki, N.; Takayanagi, H.; Shirasaka, T.; Shimpuku, T.; Takuma, Y.; Oishi, M. EP Patent 214,905, 1987; Chem. Abstr. 1987, 106, 213780.; (j) Morita, Y.; Imaki, N.; Takayanagi, H.; Shirasaka, T.; Shimpuku, T.; Takuma, Y.; Oishi, M. EP Patent 214,051, 1987; Chem. Abstr. 1987, 106, 196434.; (k) Schlosser, M.; Simig, G.; Geneste, H. Tetrahedron 1998, 54, 9023-9032; (1) Simig, G.; Schlosser, M. Synlett 1990, 50-51; (m) Anakabe, E.; Vicario, J. L.; Badía, D.; Carrillo, L.; Yoldi, V. Eur. J. Org. Chem. 2001, 4343-4352; (n) Vicario, J. L.; Badía, D.; Carrillo, L.; Anakabe, E. Tetrahedron: Asymmetry 2003, 14, 347-353.

5. (a) Nyerges, M.; Fejes, I.; Virányi, A.; Groundwater, P. W.; Töke, L. Synthesis 2001, 1479-1482; (b) Tóth, J.; Blaskó, G.; Dancsó, A.; Tőke, L.; Nyerges, M. Synth. Commun. 2006, 36, 3581-3589; (c) Ryan, J. H.; Spiccia, N.; Wong, L. S.-M.; Holmes, A. B. Aust. J. Chem. 2007, 60, 898-904; (d) D’Souza, A. M.; Spiccia, N.; Basutto, J.; Jokisz, P.; Wong, L. S.-M.; Meyer, A. G.; Holmes, A. B.; White, J. M.; Ryan, J. H. Org. Lett. 2011, 13, 486-489; (e) Padwa, A.; Dent, W. J. Org. Chem. 1987, 52, 235-244.

6. (a) Moshkin, V. S.; Sosnovskikh, V. Y.; Slepukhin, P. A.; Röschenthaler, G.-V. Mendeleev Commun. 2012, 22, 29-31; (b) Moshkin, V. S.; Sosnovskikh, V. Y.; Röschenthaler, G.-V. Tetrahedron Lett. 2012, 53, 3568-3572.

7. General procedure. A stirred mixture of the substituted benzaldehyde $(1.0 \mathrm{mmol})$, finely ground sarcosine $(0.18 \mathrm{~g}, 2.0 \mathrm{mmol})$, and paraformaldehyde $(0.12 \mathrm{~g}, 4.0 \mathrm{mmol})$ was refluxed in dry benzene $(3.3 \mathrm{~mL})$ with removal of the water formed by means of a Dean-Stark trap. Refluxing was continued for $5-8 \mathrm{~h}$. The resulting solution was evaporated in vacuo to give the intermediate 5-aryl-3-methyloxazolidine as an oily residue. This was dissolved in $6 \mathrm{M} \mathrm{HCl}(1.0 \mathrm{~mL})$ with heating at $60^{\circ} \mathrm{C}$ and then left overnight at room temperature. The mixture was extracted with $\mathrm{Et}_{2} \mathrm{O}(2 \times 3 \mathrm{~mL})$ followed by basification with an excess of a cold concentrated solution of $\mathrm{NaOH}$. The crude tetrahydroisoquinolin-4-ol 8 was extracted into $\mathrm{Et}_{2} \mathrm{O}$ or $\mathrm{CH}_{2} \mathrm{Cl}_{2}$, dried over $\mathrm{Na}_{2} \mathrm{SO}_{4}$, and evaporated to give the pure solid product.

8. 6-Methoxy-2-methyl-1,2,3,4-tetrahydroisoquinolin-4-ol (8a). White powder, yield $89 \%, \mathrm{mp} 84-86{ }^{\circ} \mathrm{C}$ (8a was previously reported in Ref. 4c without any data). IR: 3300-3000, 2944, 2836, 2796, 1610, 1586, 1500, 1439, 1371, 1284, $1169,1135,1054,1030,888,811,735,488 \mathrm{~cm}^{-1}$. ${ }^{1} \mathrm{H}$ NMR $\left(400 \mathrm{MHz}, \mathrm{CDCl}_{3}\right) \delta$ $2.35(\mathrm{~s}, 3 \mathrm{H}, \mathrm{MeN}), 2.48$ (dd, $J=11.8,2.8 \mathrm{~Hz}, 1 \mathrm{H}, 3-\mathrm{CHH}), 2.92$ (ddd, $J=11.8,2.8$, $1.0 \mathrm{~Hz}, 1 \mathrm{H}, 3-\mathrm{CHH}$ ), 3.10 (d, $J=14.5 \mathrm{~Hz}, 1 \mathrm{H}, 1-\mathrm{CHH}$ ), 3.33 (d, $J=14.5 \mathrm{~Hz}, 1 \mathrm{H}, 1-$ $\mathrm{CHH}$ ), 3.80 (s, 3H, MeO), 3.8-4.1 (br s, $1 \mathrm{H}, \mathrm{OH}), 4.54(\mathrm{t}, J=2.8 \mathrm{~Hz}, 1 \mathrm{H}, \mathrm{H}-4), 6.80$ (dd, $J=8.5,2.6 \mathrm{~Hz}, 1 \mathrm{H}, \mathrm{H}-7), 6.87$ (d, $J=8.5 \mathrm{~Hz}, 1 \mathrm{H}, \mathrm{H}-8), 6.94(\mathrm{~d}, J=2.6 \mathrm{~Hz}, 1 \mathrm{H}$, H-5). ${ }^{1} \mathrm{H}$ NMR $\left(400 \mathrm{MHz}\right.$, DMSO- $\left.d_{6}\right) \delta 2.26$ (dd, $\left.J=10.9,7.8 \mathrm{~Hz}, 1 \mathrm{H}, 3-\mathrm{CHH}\right), 2.31$ (s, $3 \mathrm{H}, \mathrm{MeN}$ ), 2.84 (ddd, $J=10.9,5.4,0.8 \mathrm{~Hz}, 1 \mathrm{H}, 3-\mathrm{CHH}$ ), 3.25 (d, $J=14.4 \mathrm{~Hz}, 1 \mathrm{H}$, $1-\mathrm{CHH}), 3.50(\mathrm{~d}, J=14.4 \mathrm{~Hz}, 1 \mathrm{H}, 1-\mathrm{CHH}), 3.72(\mathrm{~s}, 3 \mathrm{H}, \mathrm{MeO}), 4.59(\mathrm{q}, J=6.5 \mathrm{~Hz}$, $1 \mathrm{H}, \mathrm{H}-4), 5.25(\mathrm{~d}, J=6.9 \mathrm{~Hz}, 1 \mathrm{H}, \mathrm{OH}), 6.74(\mathrm{dd}, J=8.4,2.6 \mathrm{~Hz}, 1 \mathrm{H}, \mathrm{H}-7), 6.95(\mathrm{~d}$, $J=8.4 \mathrm{~Hz}, 1 \mathrm{H}, \mathrm{H}-8), 6.99$ (d, $J=2.6 \mathrm{~Hz}, 1 \mathrm{H}, \mathrm{H}-5) .{ }^{13} \mathrm{C} \mathrm{NMR}\left(126 \mathrm{MHz}, \mathrm{CDCl}_{3}\right) \delta$ $45.9,55.2,56.5,60.4,66.7,112.7,114.5,126.5,127.3,137.1,158.1$. Anal. Calcd for $\mathrm{C}_{11} \mathrm{H}_{15} \mathrm{NO}_{2}$ : C, 68.37; H, 7.82; N, 7.25. Found: C, 68.03; H, 7.82; N, 7.10.

9. 6,7,8-Trimethoxy-2-methyl-1,2,3,4-tetrahydroisoquinolin-4-ol (8c). Light yellow powder, yield $87 \%, \mathrm{mp} 107-109{ }^{\circ} \mathrm{C}(\mathbf{8 c}$ was previously reported in Ref. $4 \mathrm{~b}$ as the hydrochloride). IR: 3300-3020, 2938, 2834, 2794, 1602, 1451, 1342, 1117, 1077, 1056, 1038, 1022, 919, 900,859, 785, $580 \mathrm{~cm}^{-1} .{ }^{1} \mathrm{H}$ NMR $(400 \mathrm{MHz}$, $\left.\mathrm{CDCl}_{3}\right) \delta 2.47$ (s, 3H, MeN), 2.53 (dd, $J=11.6,2.6 \mathrm{~Hz}, 1 \mathrm{H}, 3-\mathrm{CHH}$ ), 2.8-3.0 (br s, $1 \mathrm{H}, \mathrm{OH}), 2.90$ (ddd, $J=11.6,3.2,1.0 \mathrm{~Hz}, 1 \mathrm{H}, 3-\mathrm{CHH}), 3.10$ (d, $J=15.4 \mathrm{~Hz}, 1 \mathrm{H}, 1$ $\mathrm{CHH}$ ), 3.80 (d, $J=15.4 \mathrm{~Hz}, 1 \mathrm{H}, 1-\mathrm{CHH}), 3.85,3.86,3.87$ (all s, 3H, MeO), 4.51 (t, $J=2.7 \mathrm{~Hz}, 1 \mathrm{H}, \mathrm{H}-4), 6.73(\mathrm{~s}, 1 \mathrm{H}, \mathrm{H}-5) .{ }^{13} \mathrm{C} \mathrm{NMR}\left(126 \mathrm{MHz}, \mathrm{CDCl}_{3}\right) \delta 46.0,52.8$, $55.9,60.1,60.4,60.7,67.1,107.4,121.0,131.9,141.2,149.3,152.3$. Anal. Calcd for $\mathrm{C}_{13} \mathrm{H}_{19} \mathrm{NO}_{4}$ : C, 61.64; H, 7.56; N, 5.53. Found: C, 61.24; H, 7.60; N, 5.49.

10. (a) Maffrand, J.-P. DE Patent 2,623,567, 1976; Chem. Abstr. 1977, 86, 89789.; (b) Matsuoka, M.; Oyama, T. WO Patent 2,008,120,761; Chem. Abstr. 2008, 149, 425917. 